\title{
Learning design and learning analytics in mobile and ubiquitous learning: A systematic review
}

\author{
Gerti Pishtari (D) , María J. Rodríguez-Triana (D) , Edna M. Sarmiento-Márquez, \\ Mar Pérez-Sanagustín, Adolfo Ruiz-Calleja, Patricia Santos, \\ Luis P. Prieto, Sergio Serrano-Iglesias and Terje Väljataga
}

Gerti Pishtari is a PhD candidate at the School of Digital Technologies in Tallinn University (Estonia). His research interests include mobile and ubiquitous learning, learning design, and analytics. María J. Rodríguez-Triana is a Senior Researcher at the School of Digital technologies in Tallinn University. Her research interests include learning analytics to support classroom orchestration, teacher inquiry and institutional decision making. Edna M. SarmientoMárquez is a PhD candidate at the School of Educational Sciences in Tallinn University. Her research interests include school-university partnership, adoption and implementation of educational innovation. Mar Pérez-Sanagustín is an associate professor at the Universite Paul Sabatier Toulouse III (France), a Researcher at the Institute de Recherche Informatique de Toulouse, and associate researcher at the Pontificia Universidad Católica de Chile. Adolfo RuizCalleja is a researcher at GSIC, Valladolid University (Spain). His research interests include learning analytics, distributed systems, Linked Open Data and their application in formal and informal learning. Patricia Santos is a senior researcher in the Information and Communication Technologies department at University Pompeu Fabra (Spain). Her research interests include mobile and ubiquitous learning, learning design, and design thinking. Luis P. Prieto is a senior researcher at the School of Educational Sciences in Tallinn University (Estonia). His research interests include multimodal learning and teaching analytics, teacher orchestration, and their application for teacher professional development. Sergio Serrano-Iglesias is a PhD candidate at GSIC, University of Valladolid. His research interests include smart learning environments, Internet of Things, learning design, formal and informal learning. Terje Väljataga is a senior researcher at the School of Educational Sciences in Tallinn University. Her research interests include outdoor mobile learning designs, orchestration and teacher support. Address for correspondence: Gerti Pishtari, Tallinn University, Narva maantee 2510120 Tallinn, Estonia. Email: gerti.pishtari@tlu.ee

\begin{abstract}
Mobile and Ubiquitous Learning (m/u-learning) are finding an increasing adoption in education. They are often distinguished by hybrid learning environments that encompass elements of formal and informal learning, in activities that happen in distributed settings (indoors and outdoors), across physical and virtual spaces. Despite their purported benefits, these environments imply additional complexity in the design, monitoring and evaluation of learning activities. The research literature on learning design (LD) and learning analytics (LA) has started to deal with these issues. This paper presents a systematic literature review of $\mathrm{LD}$ and $\mathrm{LA}$, in m/u-learning. Apart from providing an overview of the current research in the field, this review elicits elements of common ground between both communities, as shown by the similar learning contexts and complementary research contributions, and based on the research gaps, proposes to: address $\mathrm{m} / \mathrm{u}$-learning beyond higher education settings, reinforce the connection between physical and virtual learning spaces, and more systematically align LD and LA processes.
\end{abstract}




\section{Practitioner Notes}

What is already known about this topic

- Mobile and ubiquitous learning (m/u-learning) make use of mobile and sensor technologies to expand the boundaries where learning activities can happen.

- Learning design (LD) provides conceptual and technological tools that assist teachers to create learning environments.

- Learning analytics (LA) provides techniques for handling data that support the decision making of different stakeholders in the learning process.

- Despite the potential synergies between LD and LA, combined initiatives in m/u-learning are scarce.

What this paper adds

- A systematic overview of the fields of LD and LA in m/u-learning.

- An analysis of the relationship between LD and LA in m/u-learning.

- A list of research topics for further inquiry towards the alignment of LD and LA in $\mathrm{m} / \mathrm{u}$-learning.

Implications for practice and/or policy

- Practitioners' professional development can be complemented through the tools, methods and frameworks that were detected.

- Researchers can use the outcomes to avoid duplications and align their work with research topics that need further inquiry.

- Developers can take into account the recommendations when designing related solutions.

\section{Introduction}

The increasing usage of mobile and wireless technologies in education has played a central role in the expansion of the research fields of mobile and ubiquitous learning (m/u-learning). Both terms are used analogously (Hwang \& Tsai, 2011), and support similar educational aspects, such as learner autonomy, continuity across contexts and situational learning (Hwang \& Tsai, 2011; Traxler, 2009). The hybrid nature of $\mathrm{m} / \mathrm{u}$-learning can help in extending the boundaries where learning happens. However, it poses additional challenges for designing, monitoring and evaluating learning scenarios. On the one hand, learning design (LD) in these contexts is mainly done through authoring tools, often ad-hoc solutions connected to a specific learning space, domain, pedagogical approach, or student level. On the other hand, monitoring and evaluating learning activities in these environments are complex and demand collecting and combining data across different spaces and settings to achieve a general overview of the process (Muñoz-Cristóbal et al., 2018).

The fields of LD and Learning Analytics (LA) have provided different solutions to approach these issues. LD has focused on facilitating practitioners in sharing, modifying and reusing pedagogical plans, while LA has investigated techniques for handling learners' data to support the decision making of different actors involved in the learning process (Persico \& Pozzi, 2015). There is also evidence that both communities could complement each other, where LD can make LA more meaningful, and LA can inform decisions related to LD (Persico \& Pozzi, 2015).

However, few works incorporate both LD and LA in m/u-learning (Mangaroska \& Giannakos, 2018). Meanwhile, as m/u-learning are becoming widely adopted in a variety of settings (Hwang 
\& Wu, 2014; Pimmer, Mateescu, \& Gröhbiel, 2016), questions arise on how they support the process of LD, how LA can play a role and how both communities can support each other in these learning environments, as they do in other learning contexts (Persico \& Pozzi, 2015). In this paper, we take a wider approach by focusing on both fields of $\mathrm{LD}$ and $\mathrm{LA}$, and their contributions in designing, monitoring and evaluating learning scenarios in m/u-learning.

To the best of our knowledge, there are no articles offering a general perspective of how m/u-learning, LD and LA are related. To close the gap, this paper presents a systematic literature review on $\mathrm{LD}$ and LA, in m/u-learning. It aims to provide an overview of the current research in the field, as well as insights about the support that both communities can offer to each other in m/u-learning. It builds on a previous work that inquired about the understanding that communities of $\mathrm{LD}$ and LA have of m/u-learning (Pishtari, Rodríguez-Triana, Sarmiento-Márquez, et al., 2019). The following research questions (RQ) reflect these issues.

- (RQ1) In which learning contexts have LD and LA supported m/u-learning?

- (RQ2) What are the characteristics of the LD and LA contributions to m/u-learning?

- (RQ3) What are the commonalities, differences and synergies between LD and LA papers in $\mathrm{m} / \mathrm{u}$-learning?

Figure 1 illustrates these RQs and a series of topics that we will use to illuminate each RQ.

\section{Related work}

\section{M/u-learning}

Despite the growing research interest on m/u-learning (Fu \& Hwang, 2018), there is no consensus about their definitions (Hwang \& Tsai, 2011; Traxler, 2009). Early attempts to define both terms were techno-centric, while later ones connected them to several educational practices (Traxler, 2009). Nevertheless, m/u-learning are strongly interconnected and often used interchangeably (Hwang \& Tsai, 2011). Various authors attribute to m/u-learning similar characteristics, such as the control and autonomy over learning, situational learning and spontaneity (Hwang \& Tsai, 2011; Sharples, Taylor, \& Vavoula, 2010). Furthermore, both can underpin hybrid learning environments that foster continuity and connectivity between formal and informal learning activities (Pimmer et al., 2016). Moreover, LD/LA communities seem to consider that $\mathrm{m} / \mathrm{u}$-learning support similar aspects such as, learning across spaces, context-aware learning or learning anytime, anywhere (Pishtari, Rodríguez-Triana, Sarmiento-Márquez, et al., 2019). For these reasons, in the rest of the paper, we will count the body of research from $\mathrm{m} / \mathrm{u}$-learning as one.
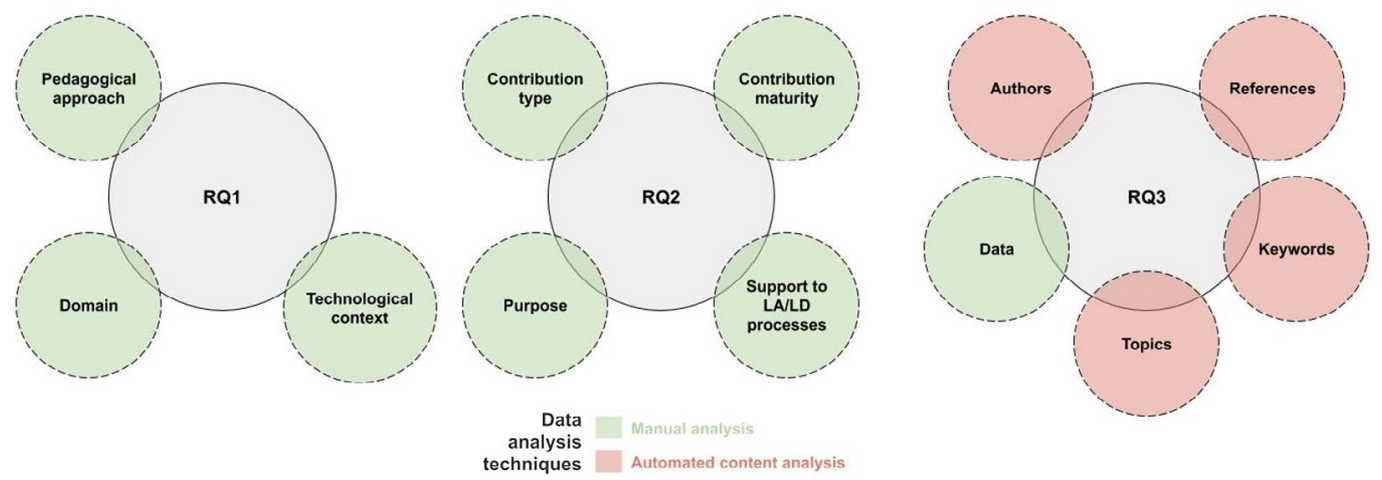

Figure 1: RQs and topics 
There exist a number of reviews in $\mathrm{m} / \mathrm{u}$-learning. Some are more transversal and focus on research trends (eg, Hwang \& Wu, 2014) which identify as open issues the need to analyze students' learning behavior and patterns. Other focus on specific educational level (eg, higher education, Pimmer et al., 2016), or particular pedagogical approaches (eg, collaborative learning, Fu \& Hwang, 2018). However, to the best of our knowledge, no work synthesizes the efforts done by LD/LA to support m/u-learning.

\section{$L D$ and $L A$}

$\mathrm{LD}$ is the sequence of learning tasks, resources and supports that a practitioner develops, which captures the pedagogical intent of a unit of study (Lockyer, Heathcote, \& Dawson, 2013). Research in LD has provided different conceptual tools (focused on representations, or supporting the sharing, reusing and enactment of designs) and technological tools (often associated with specific representations and approaches) (Persico \& Pozzi, 2015). LA investigates techniques for handling data to support the decision making of different actors involved at different stages in the learning process (Persico \& Pozzi, 2015). Examples include predictive models, or the study of learner disposition and motivations (Lockyer et al., 2013).

There is growing interest in aligning LD and LA. Both communities can support each other: LD can guide and contextualize the analysis, making them more meaningful for different stakeholders, while LA can contribute to inform design decisions and to evaluate LDs (HernándezLeo, Martinez-Maldonado, Pardo, Muñoz-Cristóbal, \& Rodríguez-Triana, 2019; Mor, Ferguson, \& Wasson, 2015). One prior systematic review of LA for LD, which identified only one work connected to m/u-learning (Mangaroska \& Giannakos, 2018). Also, from the reviews in m/u-learning, only a few that had a focus on specific educational levels included LD as a factor, while none of them discussed the role of LA.

\section{Theoretical background of $R Q s$}

Our paper offers a systematic review of the state of research on $\mathrm{m} / \mathrm{u}$-learning with a focus on $\mathrm{LD}$ and LA. To extract a structured understanding of existing LD/LA works, RQ1 and RQ2 review the learning context and the nature of the contributions. RQ3 digs into the possible commonalities, differences and synergies, as a necessary common ground for future collaborations between both fields. Subtopics chosen for RQ1 and RQ2, (Figure 1) are based on similar practices followed by existing systematic reviews in LD/LA (eg, Mangaroska \& Giannakos, 2018; Schwendimann et al., 2016). Apart from the mentioned explicit aspects (RQ1, RQ2), we also considered implicit aspects found in the publications, which can inform our discussion about RQ3. Subtopics for RQ3 were selected for their relevance in Scholarly Network Analysis (Pawar et al., 2019).

\section{Methodology}

Following the guidelines proposed by Kitchenham and Charters (2007) for systematic reviews, we selected seven databases in technology enhanced learning (ACM Digital-Library [http:// dl.acm.org/dl.cfm], AISEL [http://aisel.aisnet.org], IEEE XPLORE [http://ieeexplore.ieee.org/ Xplore/home.jsp], SpringerLink [http://link.springer.com], ScienceDirect [http://www.sciencedir ect.com], Scopus [http://www.scopus.com/home.uri], Wiley [http://onlinelibrary.wiley.com]) and Google Scholar for relevant grey literature. The query reflects the kinds of learning we were focusing on and the research field where the proposal was framed, resulting in: (LD" OR "LA") AND ("mobile learning" OR "ubiquitous learning"). Running this query on April 4, 2019, we obtained 1722 papers. While no time constraints were imposed, the results were from 2008 to 2019. To standardize the process, we restricted the query to the title, abstract and keywords of 
each paper. The filtering process was reported in Pishtari, Rodríguez-Triana, Sarmiento-Márquez, et al. (2019) and resulted in 54 papers.

Six reviewers were involved in the process. To have a common understanding about the paper annotation process, first all participants reviewed the same four papers, clarified the doubts, and then proceeded with the remaining ones (evenly distributed). A Google Form was used for the process (http://bit.ly/LALDMULform). Data resulting from the review were checked for inconsistencies (at least by two authors per paper), which were later discussed with the whole group. The list of papers and relevant information about the review is presented in Table 1, and in its extended version (http://bit.ly/LALDinMUL). Figure 2 summarizes the review process.

To answer our RQs, we performed multiple qualitative and quantitative analyses of the evidence available in the 54 papers. Qualitative analysis followed a human-driven, top-down approach (in green in Figure 1) of synthesizing the conclusions of the research team about that particular topic for each of the papers, and visualizing the results graphically. For RQ2 this was done through content analysis, guided by existing LD/LA frameworks, or models (presented in Results, subsection Contributions). We complemented this vision with quantitative bottom-up computational approaches (in red in Figure 1). Particularly, social networks were constructed for our dataset (using VOSviewer [https://www.vosviewer.com/] and the igraph package for R [https://igraph. org]), to understand the cohesion and degree of separation between the two research communities (eg, networks of co-authorship, or networks of co-occurrence of keywords in a paper). The content of the papers themselves was analyzed computationally, using topic modeling techniques such as Latent Dirichlet Allocation and the topics were interpreted by triangulation of the main topic keywords and the human-coded knowledge of each paper from the manual analysis.

The chosen query might have left out contributions relevant to this work due to alternative terminology (eg, seamless learning, scripting or educational data mining). Also, the computational analyses could have taken advantage of recent advances in natural language processing and deeper social network analyses (eg, networks and clusters of co-references between papers).

\section{Results}

This section and subsections present the results organized, respectively, along the RQs. From 54 papers, 28 (51.9\%) referred to LD, $23(42.6 \%)$ to LA, and $3(5.6 \%)$ to both. From the three cross-community papers, two enquired about LA for LD (Hernández-Leo \& Pardo, 2016; Melero, Hernández-Leo, Sun, Santos, \& Blat, 2015), while one discussed elements from both fields without aligning them (Mikroyannidis, Gómez-Goiri, Smith, \& Domingue, 2018). In addition, one LA paper implemented a mixed approach, including analytics decisions at design time and a design-driven analysis (Muñoz-Cristóbal et al., 2018).

\section{Learning context (RQ1)}

In Pishtari, Rodríguez-Triana, Sarmiento-Márquez, et al. (2019) we extracted information about educational settings and learning spaces. Despite the emphasis that m/u-learning has on informal learning and learning anytime, anywhere, both LD and LA communities have focused on formal settings, mostly in higher education (easily accessible to researchers). While in most of the papers the learning process happened across physical and virtual spaces (39), for papers that included a learning activity, it usually took place both indoor and outdoor simultaneously (22). In addition, to answer RQ1, we grouped the papers based on domain, pedagogical approach and technological context. 


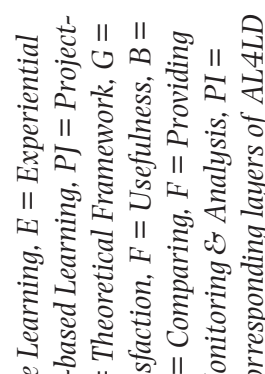

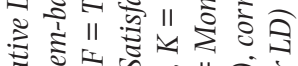

ㄴ.

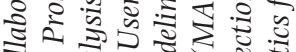

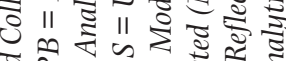
ป

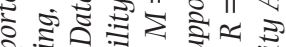

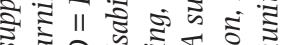

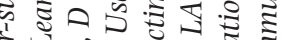

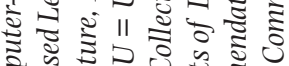
苛

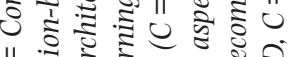
II (2) 011 可 ๖ ㄴ. डิ उี హู

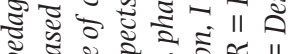
는

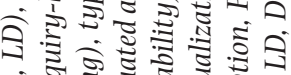
-

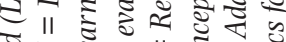
는

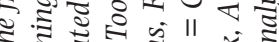

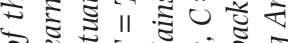
ज的式

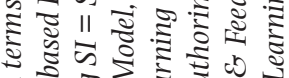

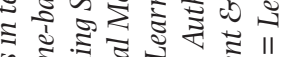
ป ฐ

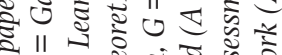
సٓ

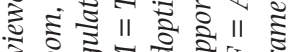
ऽ ฐ ฐ จ는

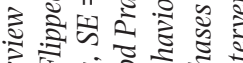
के

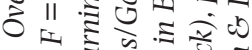

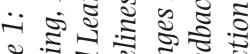

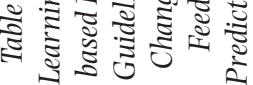

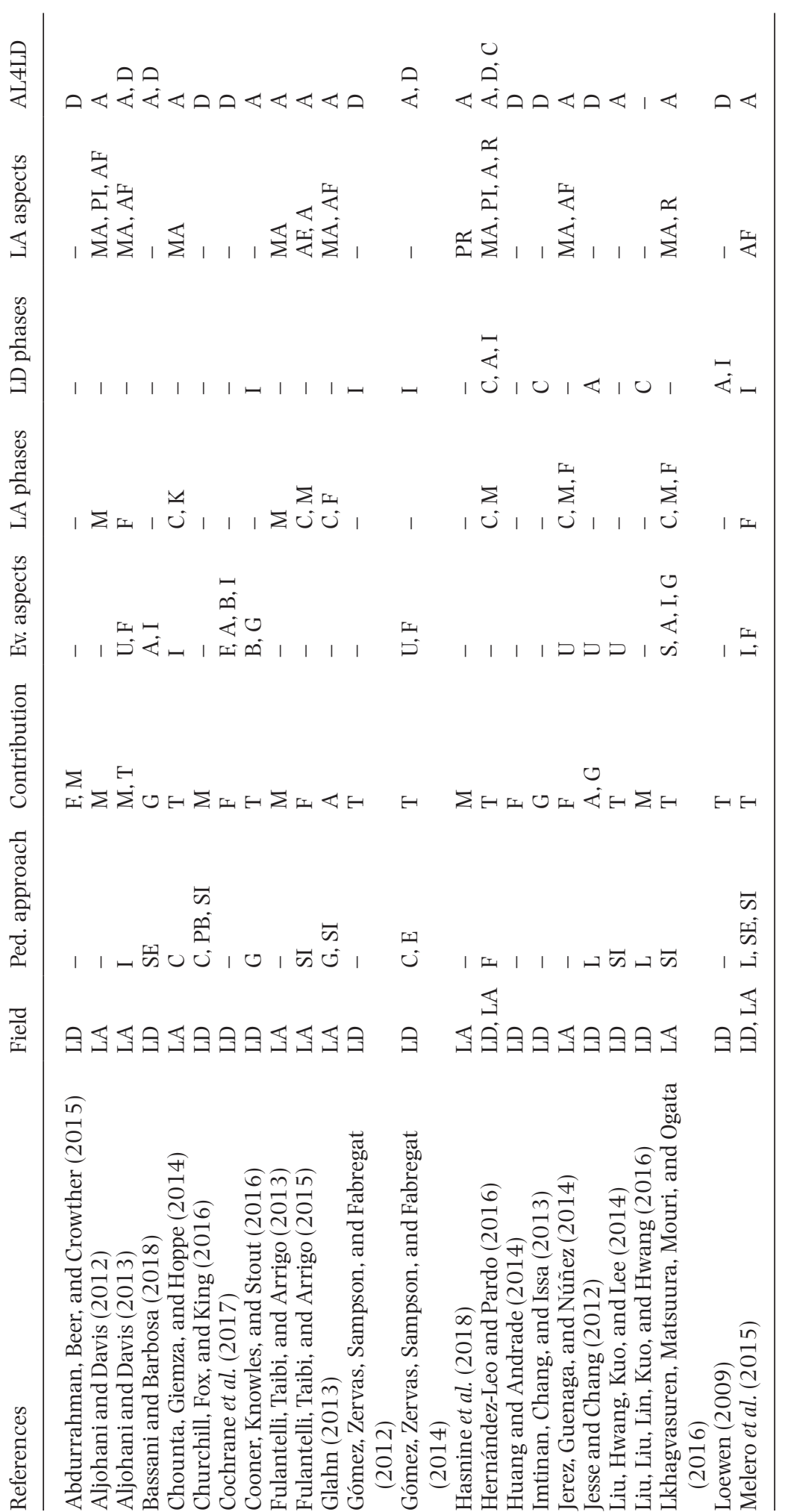




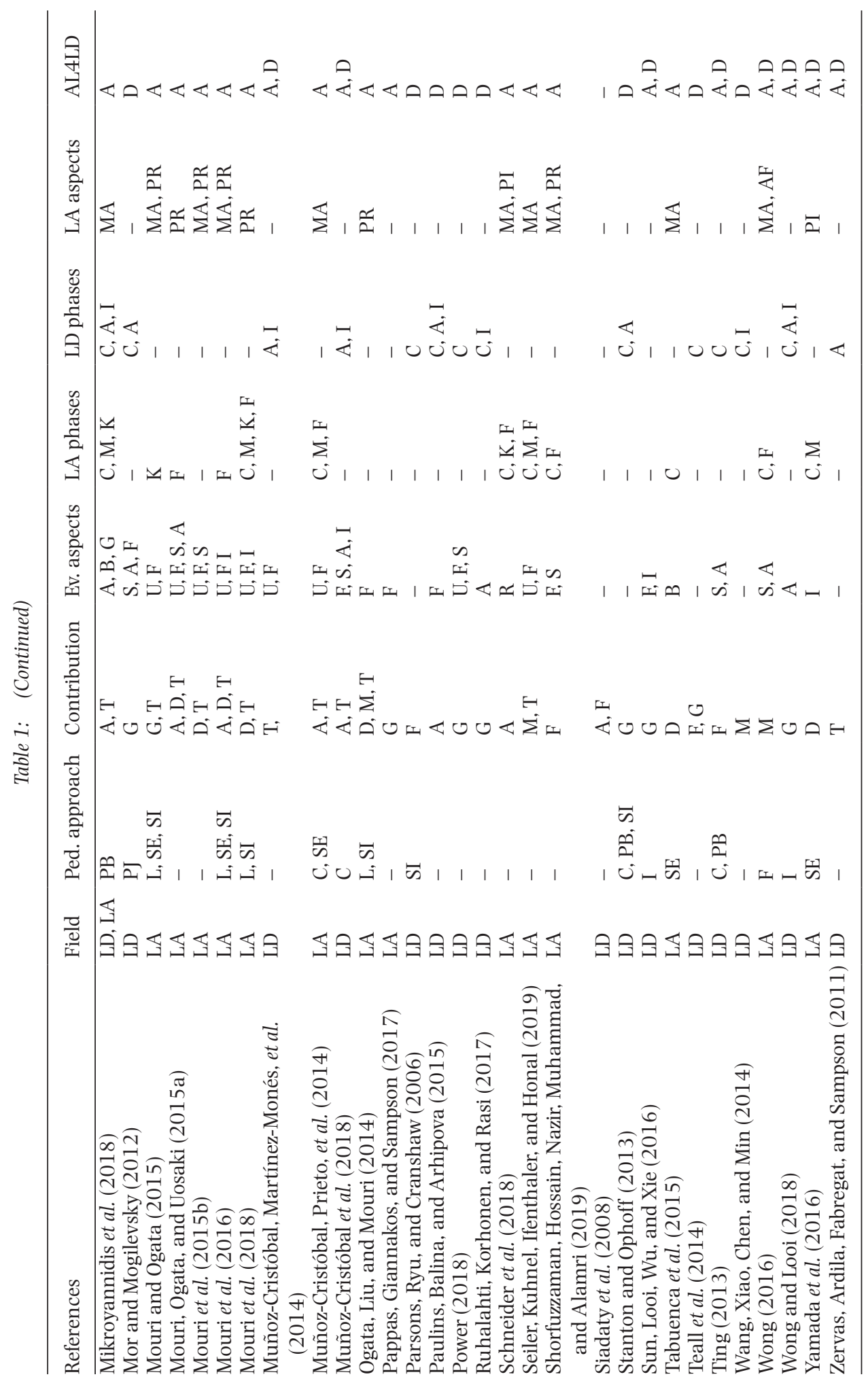




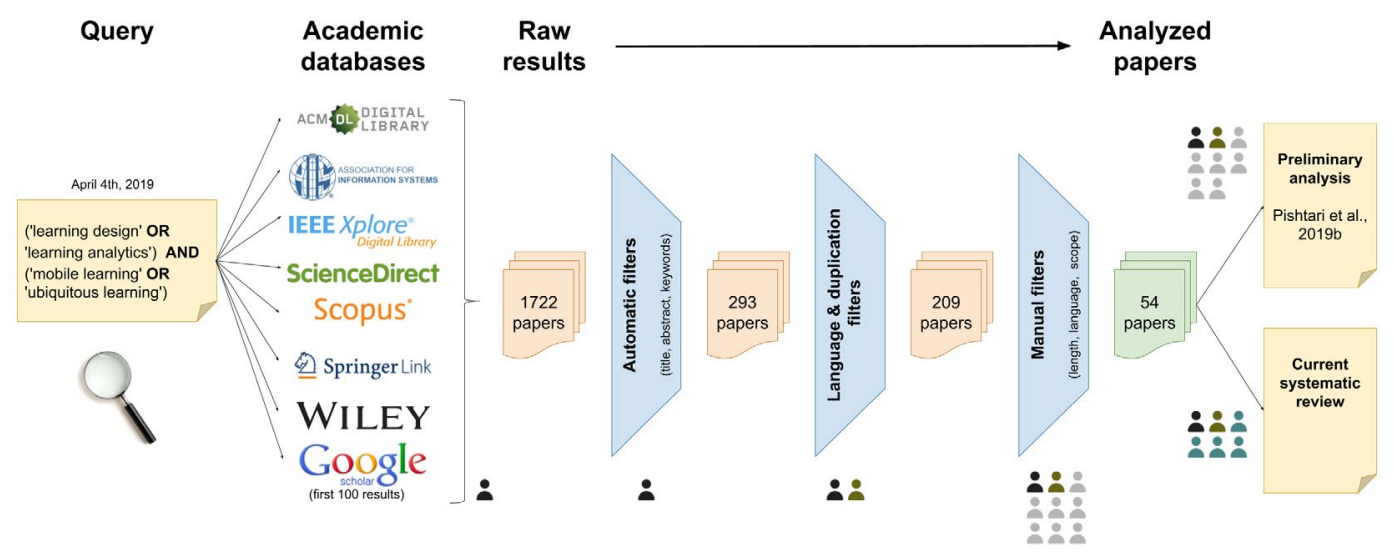

을 Reviewers involved

Figure 2: Stages of the systematic review

\begin{tabular}{|c|c|c|c|c|c|c|c|c|c|c|c|c|c|c|c|}
\hline \multirow[b]{2}{*}{ Pedagogical approach } & \multirow[b]{2}{*}{ Papers } & \multicolumn{14}{|c|}{ Number of papers per category (LD, LD \& LA, LA) } \\
\hline & & 6 & 5 & 4 & 3 & 2 & 1 & 1 & $\mathbf{1}$ & 2 & 3 & 4 & 5 & 6 & 7 \\
\hline Situated Learning & 12 & & & & & & & & & & & & & & \\
\hline Computer-supported Collaborative Learning & 7 & & & & & & & & & & & & & & \\
\hline Location-based Learning & 7 & & & & & & & & & & & & & & \\
\hline Self-regulated Learning & 7 & & & & & & & & & & & & & & \\
\hline Problem-based Learning & 4 & & & & & & & & & & & & & & \\
\hline Inquiry-based Learning & 2 & & & & & & & & & & & & & & \\
\hline Game-based Learning & 2 & & & & & & & & & & & & & & \\
\hline Flipped Classroom & 2 & & & & & & & & & & & & & & \\
\hline Experiential Learning & 1 & & & & & & & & & & & & & & \\
\hline Project-based Learning & 1 & & & & & & & & & & & & & & \\
\hline
\end{tabular}

LD papers $\quad$ LA \& LD papers $\quad$ LA papers

Figure 3: Pedagogical approach

Domain

The main focus has been on facilitating language learning (13; 24.1\%). For example, Mouri, Ogata, and Uosaki (2015b) proposed Scroll, a language application that recommends content, based on the context and the location. However, in 38.9\% (21) of the cases, the domain went unspecified. There were no significant differences when considering LD/LA papers separately, apart that teacher training appears only in LD papers (3 out of 31).

Pedagogical approach

Almost half of the studies did not explicitly mention the pedagogical approach, while from the rest situated learning was the most mentioned (Figure 3). 
Technological context

In $26(48.1 \%)$ papers the technological context included a software, in $12(22.2 \%)$ an underlying architecture, in 7 (13\%) both, while in 9 (16.7\%) it was not specified. The most common devices included portable smart devices $(47 ; 87 \%)$ and personal computers $(14 ; 26 \%)$.

Contributions (RQ2)

We grouped the papers based on their explicit contributions, and main supported aspects of $\mathrm{m} / \mathrm{u}$-learning. For each paper, we evaluated the maturity of the contribution based on the number and type of evaluations, the methodology used, the number of participants and duration. Furthermore, we used known LD/LA frameworks and models to guide content analysis to extract intended contributions of the papers, as well as the kind of support that they offered (Figure 4).

Type of contributions

Most papers offered a tool as a contribution (22; 40.7\%). For example, QuestInSitu is a location-based tool which incorporates a LA dashboard (Melero et al., 2015), while GLUEPS-AR helps teachers deploying and enacting LDs in virtual and augmented environments (Muñoz-Cristóbal, Martínez-Monés, et al., 2014). Apart from tools, LD has produced more guidelines/good practices (11), and theoretical frameworks (7), see for instance Teall, Wang, Callaghan, and Ng (2014), listing guidelines and frameworks in m-learning, or Siadaty et al. (2008) presenting an ontology-based framework for context-aware m-learning. LA has focused on data analysis (7), as in Tabuenca, Kalz, Drachsler, and Specht (2015) exploring the effects of monitoring time devoted to learning, as well as in theoretical models (7), such as Aljohani and Davis (2012).

Regarding the specific m/u-learning aspects, as defined in Pishtari, Rodríguez-Triana, SarmientoMárquez, et al. (2019), we extracted how LD/LA papers explicitly supported them (Figure 5). The emphasis has been on supporting learning with mobile technologies. Nevertheless, this happened

\begin{tabular}{|c|c|c|c|c|c|c|c|c|c|c|c|c|c|c|c|c|c|c|c|c|c|c|c|c|c|c|}
\hline \multirow[b]{2}{*}{ Contribution } & \multirow[b]{2}{*}{ Papers } & \multicolumn{25}{|c|}{ Number of papers per category (LD, LD \& LA, LA) } \\
\hline & & 11 & 10 & 9 & 8 & 7 & 6 & 5 & 4 & 3 & 2 & 1 & 1 & 2 & 3 & 1 & 2 & 3 & 4 & 5 & 6 & 7 & 8 & 9 & 10 & 11 \\
\hline Tool & 22 & & & & & & & & & & & & & & & & & & & & & & & & & \\
\hline Architecture & 9 & & & & & & & & & & & & & & & & & & & & & & & & & \\
\hline Guidelines/Good practices & 13 & & & & & & & & & & & & & & & & & & & & & & & & & \\
\hline Theoretical Model & 11 & & & & & & & & & & & & & & & & & & & & & & & & & \\
\hline Theoretical Framework & 10 & & & & & & & & & & & & & & & & & & & & & & & & & \\
\hline Data-analysis & 7 & & & & & & & & & & & & & & & & & & & & & & & & & \\
\hline
\end{tabular}

Figure 4: Type of contributions

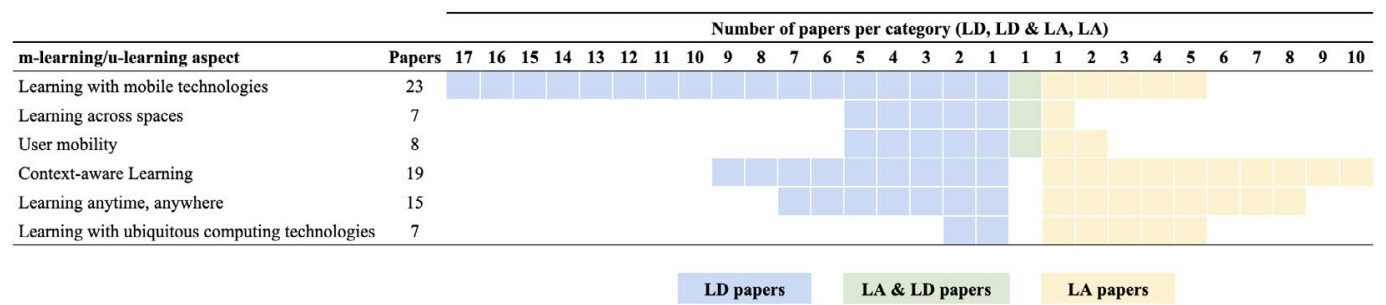

Figure 5: m/u-learning aspects according to Pishtari, Rodríguez-Triana, Sarmiento-Márquez, et al. (2019) 
mainly in LD papers and was largely connected to works written when the characteristics associated with $\mathrm{m} / \mathrm{u}$-learning were more techno-centric.

In addition, the contributions in LD papers targeted mainly teachers (25) and instructional designers (15), while both learners (15) and teachers (15) were the target of LA (Pishtari, Rodríguez-Triana, Sarmiento-Márquez, et al., 2019).

\section{Maturity}

From 54 papers, 24 (43.4\%) were journal publications, 7 (13.2\%) book chapters, $13(24.5 \%)$ full conference papers, 9 (17\%) short conference papers and 1 (1.9\%) workshop paper. Also, 19 (35.2\%) did not contain an evaluation (most of which LD), while the rest included one (24;44.4\%), or more than one $(11 ; 20.4 \%)$. Most of the evaluations were case studies (30 out of 35 papers including evaluations), two papers included focus groups, while evaluation of experts and technical validation was mentioned once. The methodology in 15 papers was quantitative, in 7 qualitative and in 13 mixed. Figure 6 shows the evaluated aspects of the contributions grouped for LD/LA papers. Both communities have focused mostly on aspects such as usefulness, usability and user satisfaction.

Thirty-two studies mentioned participants involved in the evaluations (usually more than 15 participants). Participants were teachers (17) and students (8), which leaves space for further inquiry about other stakeholders with an interest in LD/LA (Pishtari, Rodríguez-Triana, \& Väljataga 2019). The duration of the evaluation was not described in 12 (out of 35) papers. From the ones that described it, 4 lasted less than 2 days, 5 a few weeks, 10 several months and 2 more than 1 year.

\section{Support to LD processes}

To understand how the reviewed papers supported LD, we classified them according to three design phases proposed by Hernández-Leo, Asensio-Pérez, Derntl, Prieto, and Chacón (2014), conceptualizing, authoring and implementation, considering only phases explicitly mentioned by the authors. There was an even distribution between conceptualizing (14), authoring (11) and implementation support (12). However, most of the papers focused on specific phases of the design process, and only four supported the whole process (Figure 7).

Support to LA processes

To understand how the type of support that LA had provided to $\mathrm{m} / \mathrm{u}$-learning could be aligned with LD practices, we grouped LA papers based on the model proposed by Rodríguez-Triana, Martínez-Monés, Asensio-Pérez, and Dimitriadis (2015). Apart from comparing (5), there is an

\begin{tabular}{|c|c|c|c|c|c|c|c|c|c|c|c|c|c|c|c|c|c|c|c|c|c|}
\hline \multirow[b]{2}{*}{ Evaluated aspects } & \multirow[b]{2}{*}{ Papers } & \multicolumn{20}{|c|}{ Number of papers per category (LD, LD \& LA, LA) } \\
\hline & & 8 & 7 & 6 & 5 & 4 & 3 & 2 & 1 & 1 & 1 & 2 & 3 & 4 & 5 & 6 & 7 & 8 & 9 & 10 & 11 \\
\hline Impact on learning & 10 & & & & & & & & & & & & & & & & & & & & \\
\hline Changes in behavior & 4 & & & & & & & & & & & & & & & & & & & & \\
\hline Learning gains & 3 & & & & & & & & & & & & & & & & & & & & \\
\hline Adoption & 11 & & & & & & & & & & & & & & & & & & & & \\
\hline Usefulness & 20 & & & & & & & & & & & & & & & & & & & & \\
\hline Usability & 14 & & & & & & & & & & & & & & & & & & & & \\
\hline User satisfaction & 9 & & & & & & & & & & & & & & & & & & & & \\
\hline Reliability (technical) & 1 & & & & & & & & & & & & & & & & & & & & \\
\hline
\end{tabular}




\begin{tabular}{c|ccc}
\hline Papers & \multicolumn{2}{c}{ Phases of a LD process } \\
\hline 6 & conceptualization & & \\
\hline 2 & & authoring & \\
\hline 4 & & & implementation \\
\hline 2 & conceptualization & authoring & \\
\hline 2 & conceptualization & & implementation \\
\hline 3 & & authoring & implementation \\
\hline 4 & conceptualization & authoring & implementation \\
\hline
\end{tabular}

Figure 7: LD papers grouped by the phases of LD process

\begin{tabular}{|c|c|c|c|}
\hline Papers & & Phases of a LA process & \\
\hline 1 & collecting & & \\
\hline 2 & & modeling & \\
\hline 1 & & comparing & \\
\hline 4 & & & providing feedback \\
\hline 3 & collecting & modeling & \\
\hline 1 & collecting & comparing & \\
\hline 3 & collecting & & providing feedback \\
\hline 1 & collecting & comparing & \\
\hline 4 & collecting & modeling & providing feedback \\
\hline 1 & collecting & comparing & providing feedback \\
\hline 1 & collecting & comparing & providing feedback \\
\hline
\end{tabular}

Figure 8: LA papers grouped by the script aware monitoring process

evenly distributed number of papers dealing with collecting (15), modeling (11) and providing feedback (13). As it happened with the LD support, most of the papers focused on specific phases and only one of them covered the whole LA process (Figure 8).

Purpose

We used different frameworks to understand the task that the reviewed papers were supporting. Figure 9 categorizes the contributions based on the LA Reference Model (Chatti, Dyckhoff, Schroeder, \& Thüs, 2013). Most of LA papers focused on monitoring and analysis (18 out of 26), while tutoring and mentoring, adaption and reflection were barely (or not) mentioned. 


\begin{tabular}{|c|c|c|c|c|c|c|c|c|c|c|c|c|c|c|c|c|c|c|c|}
\hline LA Reference Model Process & Papers & 1 & 2 & 3 & 4 & 5 & 6 & 7 & 8 & 9 & 10 & 11 & 12 & 13 & 14 & 15 & 16 & 17 & 18 \\
\hline Monitoring \& Analysis & 18 & & & & & & & & & & & & & & & & & & \\
\hline Prediction \& Intervention & 4 & & & & & & & & & & & & & & & & & & \\
\hline Tutoring \& Mentoring & - & & & & & & & & & & & & & & & & & & \\
\hline Assessment \& Feedback & 7 & & & & & & & & & & & & & & & & & & \\
\hline Adaptation & 2 & & & & & & & & & & & & & & & & & & \\
\hline Personalization \& Recommendation & 8 & & & & & & & & & & & & & & & & & & \\
\hline Reflection & 2 & & & & & & & & & & & & & & & & & & \\
\hline
\end{tabular}

Figure 9: LA papers grouped by the LA reference model processes covered

\begin{tabular}{|c|c|c|c|c|c|c|c|c|c|c|c|c|c|c|c|c|}
\hline Type & Examples & Papers & 1 & 2 & 3 & 4 & 5 & 6 & 7 & 8 & 9 & 10 & 11 & 12 & 13 & 14 \\
\hline Action-related & Age, Prior education & 12 & & & & & & & & & & & & & & \\
\hline Learner-related & Login time, Time spent on a task & 5 & & & & & & & & & & & & & & \\
\hline Content-related & Topic covered in the uploaded material & 12 & & & & & & & & & & & & & & \\
\hline Context-related & Location & 7 & & & & & & & & & & & & & & \\
\hline Result-related & Score & 14 & & & & & & & & & & & & & & \\
\hline Social-related & Network of communications between learners & 2 & & & & & & & & & & & & & & \\
\hline
\end{tabular}

Figure 10: LA papers grouped by the type of indicators reported

Schwendimann et al. (2016) group LA indicators into six types (see column Type in Figure 10), which guided our categorization of the indicators explicitly mentioned in the papers. We noticed some content and context-related indicators more specific to the case of m/u-learning, like learners location or content accessed by learners in specific locations. Furthermore, specific groups indicators, such as social-related ones, appeared rarely.

From a LD perspective, we grouped the papers based on the AL4LD framework (Hernández-Leo et al., 2019) that defines three layers where analytics can support the process of design (Figure 11). Most LA papers supported processes connected to learning orchestration (LA for LD layer), while LD contributions targeted mainly the Design Analytics layer. Aspects about Community Analytics were largely unexplored, considered only by Hernández-Leo and Pardo (2016) that inquired the integration of LA with a community platform for LD. The AL4LD-based classification showed that LA contributions could be further aligned with LD processes and support different stakeholders. For instance, Melero et al. (2015) and Schneider, Di Mitri, Limbu, and Drachsler (2018) use sensors to collect, compare information and provide feedback to students and teachers, which could be linked to the $\mathrm{LD}$ processes of authoring and implementation presented in a similar environment as in Muñoz-Cristóbal, Prieto, et al. (2014).

Relations between $L D$ and $L A(R Q 3)$

We explored the relations between LD and LA through five main aspects (suggested by Pawar et al., 2019): network of authors of the papers, references, keywords, topics of the papers, data used in the $\mathrm{LD} / \mathrm{LA}$ solutions proposed in the papers.

Authors

The social network of the co-authoring revealed that there were multiple clusters of collaborators (Figure 12). Moreover, except for three mixed clusters, most of the authors interacted only with researchers from the same domain. The scarce LD-LA interaction may entail low knowledge transfer between the two domains and limited exploitation of potential synergies. 


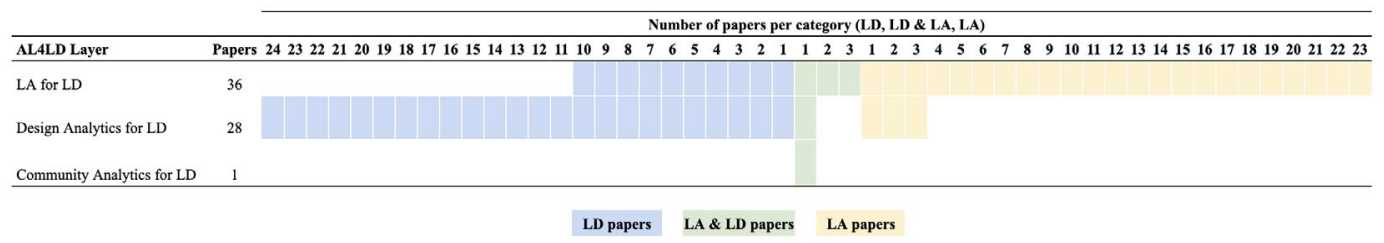

Figure 11: Papers grouped by the AL4LD framework
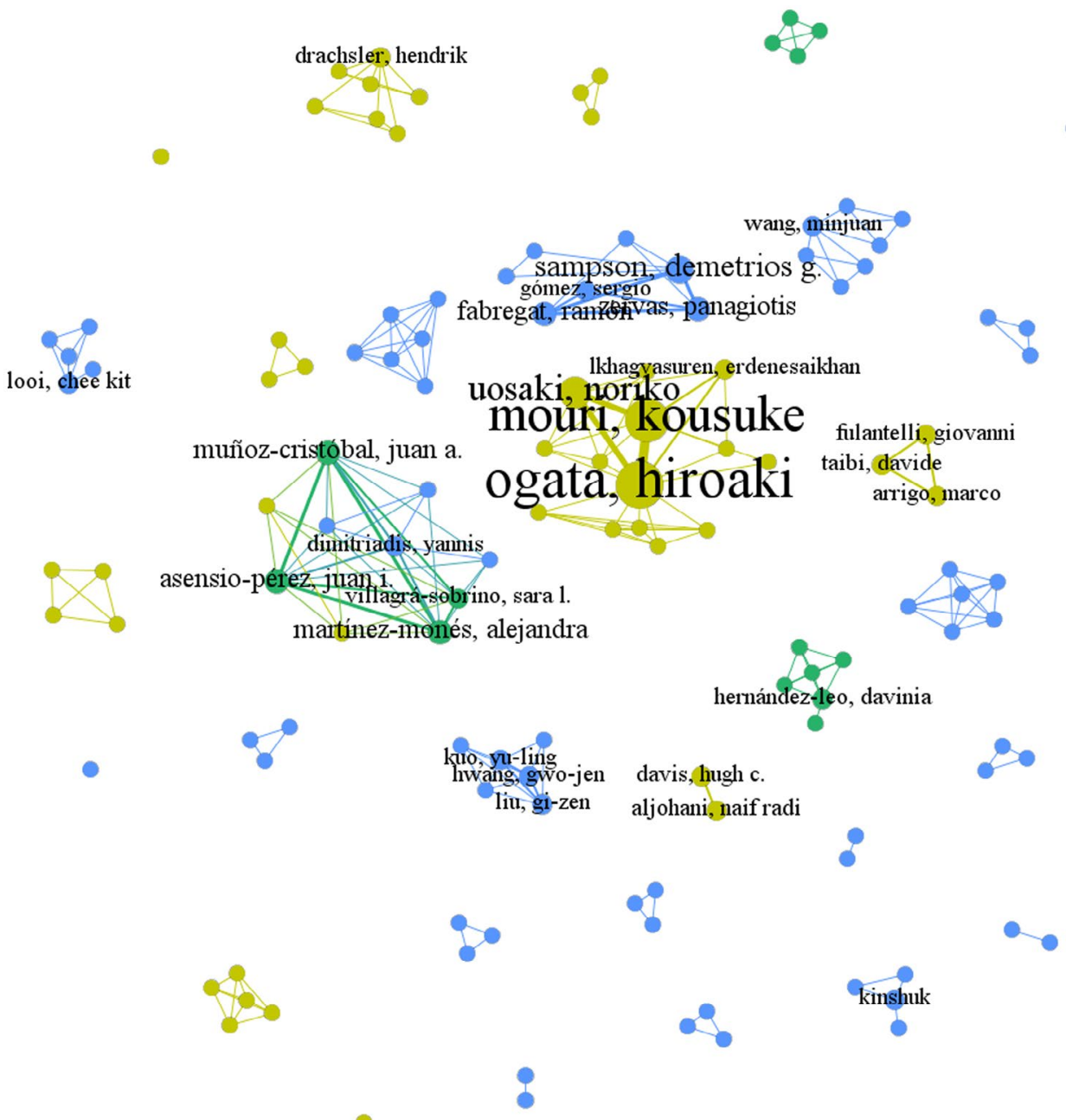

Figure 12: Clusters of co-authorship. Blue, yellow and green nodes correspond, respectively, to LD, LA and LDELA authors

\section{References}

References appearing in the papers inform about the common literature. The 10 most-cited references were mainly shared among LA papers, while LD papers did not have many common related works (with each other, and with LA papers) (Figure 13). This could also be generally observed in the references of the dataset (only 42 references, out of 1636 , were shared by at least one LD 


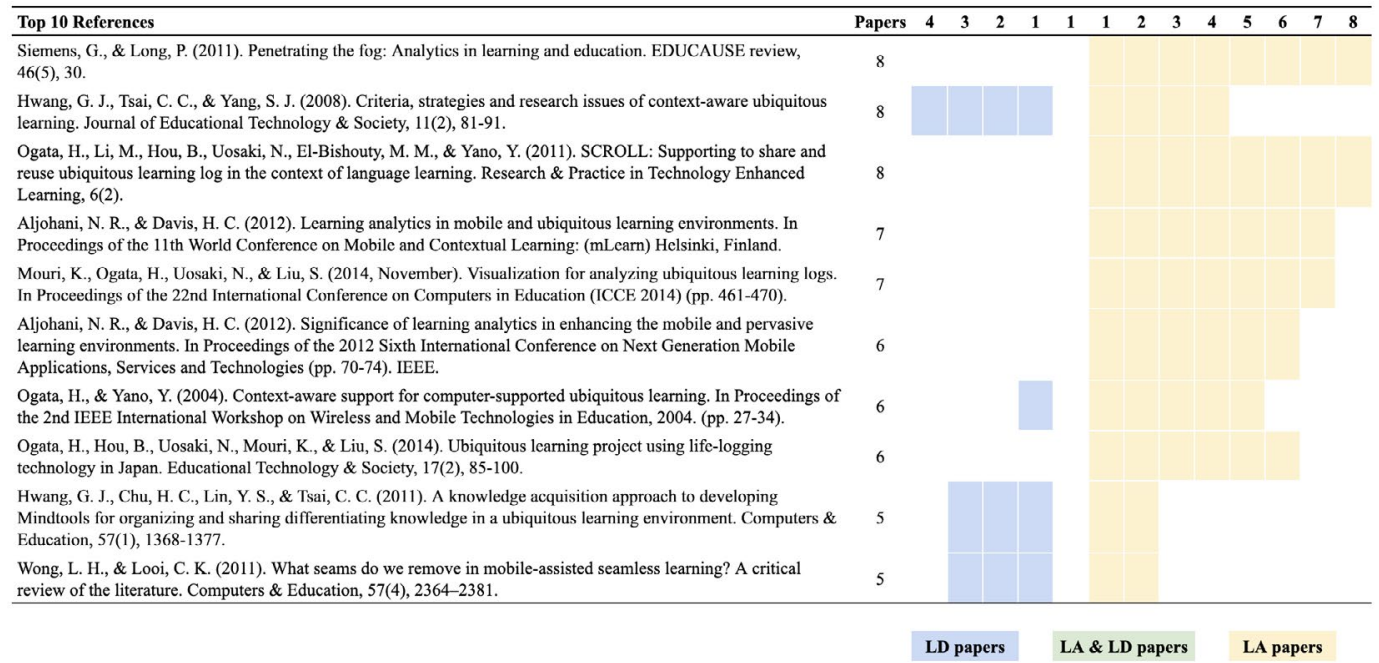

Figure 13: Top 10 references among the 54 papers, and number of citations from LD and LA papers

and LA paper). Interestingly, looking at the topics addressed in each one of those highly cited references, six covered transversal $\mathrm{m} / \mathrm{u}$-learning aspects, three referred to the application of LA in $\mathrm{m} / \mathrm{u}$-learning contexts and one of the most cited was an early LA paper about the usage of LA for evidence-based decision making. In addition, to better understand to what extent the papers were connected through the references, we applied Social Network Analysis techniques. The results revealed that only one paper was not connected to the rest by shared references. Thus, based on the number of common references and their content, there were no central pieces guiding and illustrating the LD-LA connections.

Keywords

Figure 14 shows a social network of co-occurrences of the keywords specified by the authors of the papers. As expected, keywords related to m/u-learning were quite prominent and well connected. LA terms were less numerous (but more consistently used), while LD-related keywords varied more. In contrast with LA, LD seemed to be more related to the context (eg, flipped classroom, blended learning) and less to the pedagogical or learning approach (eg, collaboration, self-regulated learning). Regarding the connection between both, few papers used LD and LA simultaneously in the keywords.

Topics

Through automatic analysis of the body of the papers (excluding references and bios), we explored the emergent topics. The number of topics was selected using the ldatuning $\mathrm{R}$ package (https://cran.r-project.org/web/packages/ldatuning/), which triangulates between four different metrics to find the most "natural" number of topics in a set of documents (which lead to 11 topics). Figure 15 shows a 2-dimensional representation of these topics (using Principal Components Analysis). To interpret them (labels in Figure 15), we combined our insights looking at the most frequent terms per topic, and our qualitative knowledge about the papers allocated to each topic. We noticed several clusters of majoritarily LA-related papers, focusing on either self-regulated $\mathrm{m}$ /u-learning, or more conceptual frameworks/models. We also saw a series of LD-related clusters, tackling mostly formal learning. Interestingly, six other clusters were more mixed, indicating certain interests transversal to both communities (eg, augmented reality, classroom contexts), 


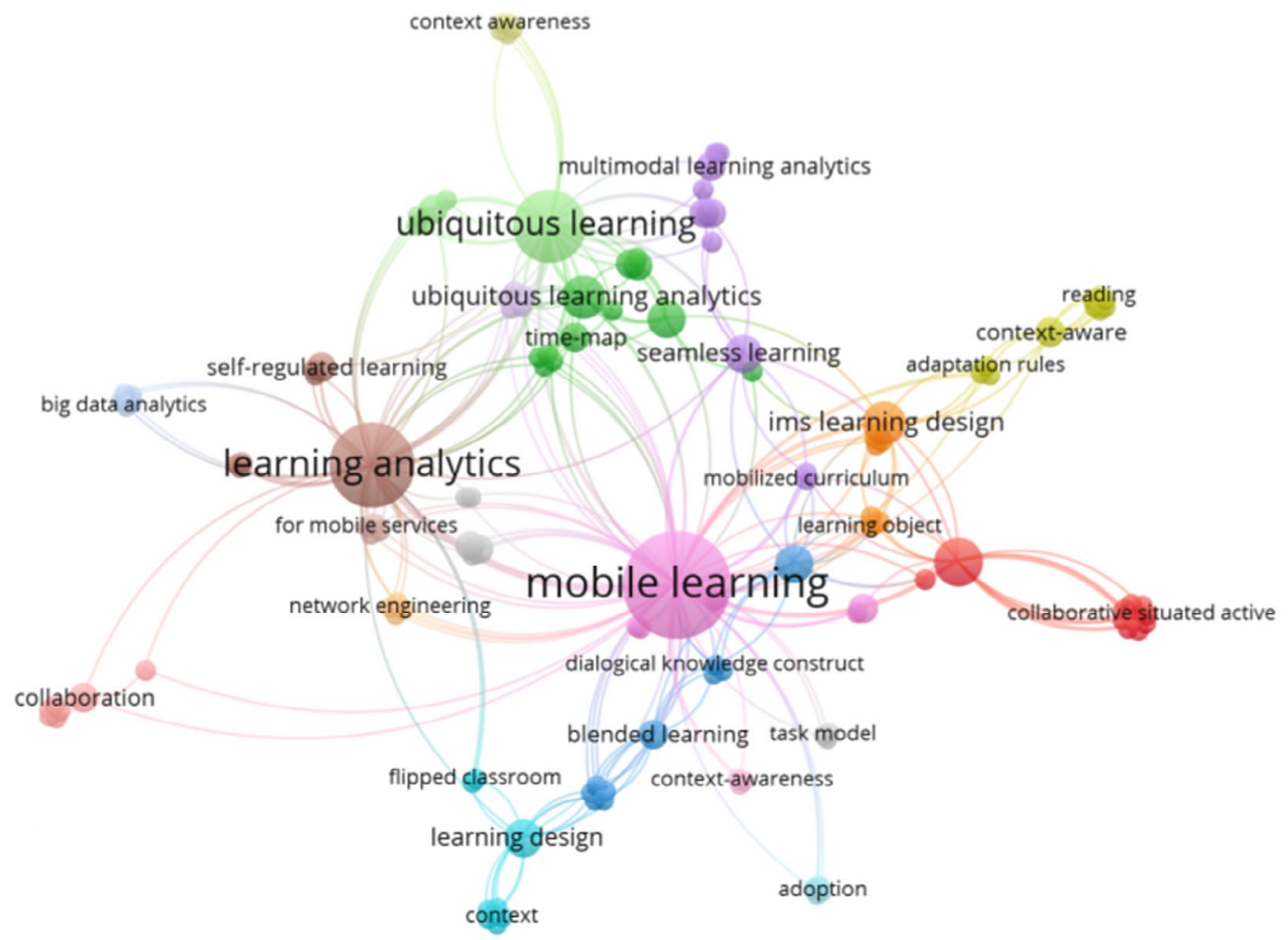

Figure 14: Network of keywords used in the 54 papers

as well as the kinds of higher level contributions relevant in both areas (including technological frameworks, architectures and guidelines).

Data

To inform how each community models $\mathrm{m} / \mathrm{u}$-learning in practice, we extracted from the papers data sources and data explicitly used in the contributions. Both communities have common data elements, eg, about participants, the content they generate or assessment data (Figure 16). Theoretical aspects—-such as the pedagogical approach, as well as the context and participant roles - are part of pure LD solutions, while LA solutions track more thoroughly not only digital but also physical traces. LD often benefits from ad-hoc data generated by the stakeholders, while LA relies mainly on digital content, logs and sensors. Since both communities already use data that the other is not exploiting (left and right areas, Figure 16), these two areas represent opportunities for practical synergies between them in the short term.

\section{Discussion}

Regarding RQ1, LD/LA communities have considered similar learning contexts in m/u-learning (mostly in higher education, combining physical and virtual spaces), which constitutes a necessary common ground for possible collaborations. Further work from each community is required to support m/u-learning in authentic settings. K12 could be a short-term target for LD since both lessons and curriculum design play a strong role in formal learning. Then, LA could contribute by supporting teachers and students to monitor the process towards the achievement of the 
Topics space, colored by topic, shapes by area

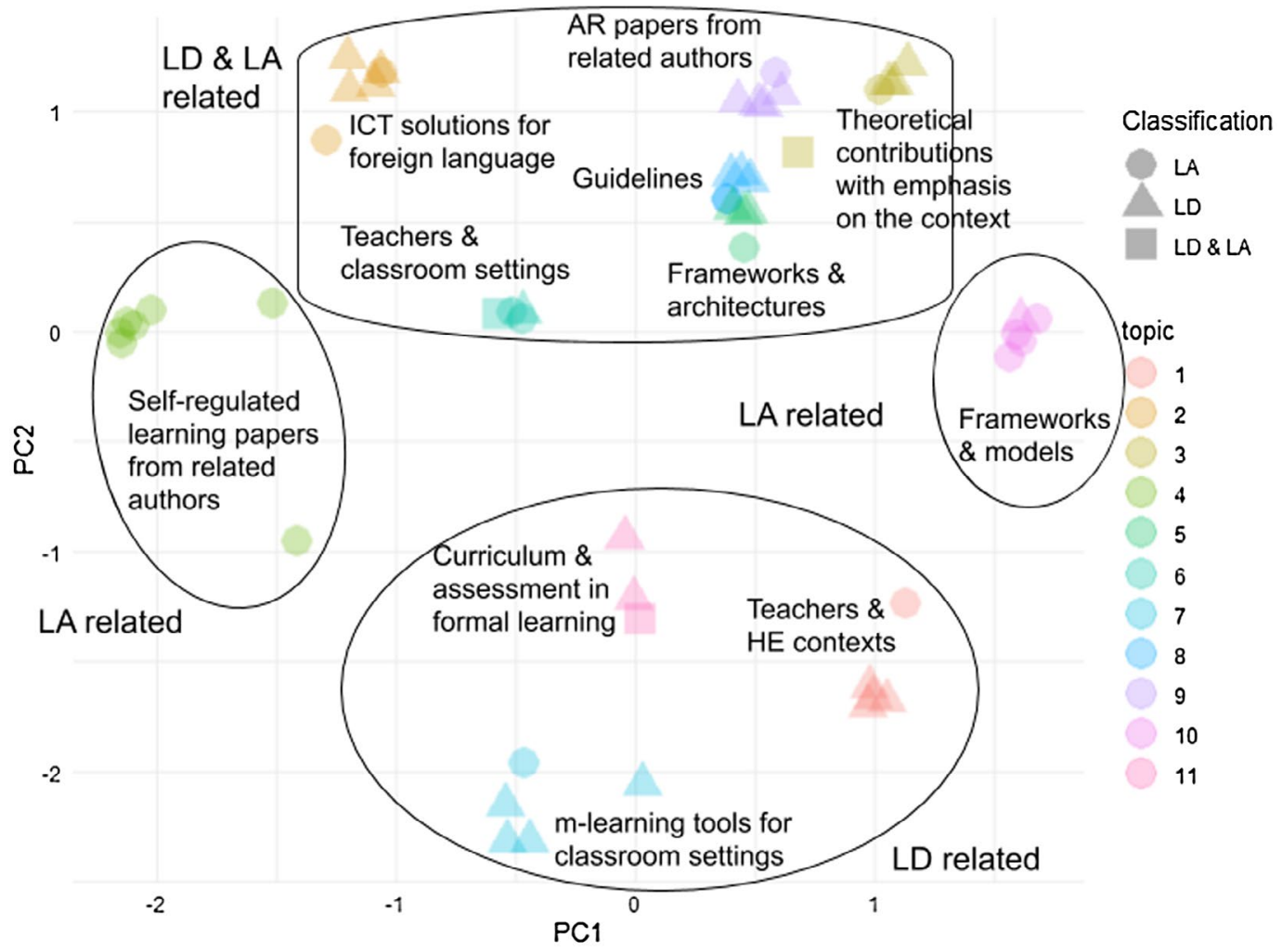

Figure 15: Visual representation of the computationally generated paper topics

learning goals, as well as to assess the added value of $\mathrm{m} / \mathrm{u}$-learning solutions (as suggested by Rodríguez-Triana et al., 2015). In the case of informal and self-regulated learning, core interests of m/u-learning (Pimmer et al., 2016), LA could help: first, addressing the lack of awareness that multiple stakeholders have due to the lack of face-to-face interaction; second, integrating pedagogically grounded analytics to help with the lack of $\mathrm{LD}$ background that stakeholders may have.

The low number of papers explicitly mentioning their pedagogical approach could be related to proposals that are applicable in multiple contexts, but could also signal a disregard for this aspect, with implications for the adoption of such technologies (eg, improper use). Furthermore, despite the emphasis of $\mathrm{m}$ /u-learning on learning in distributed settings, designing and understanding learning across spaces is still a work in progress, especially regarding the physical space. Only a few contributions integrated sensors, despite being a classic technology in m/u-learning. Considering recent trends towards multimodality in LA (Ochoa, 2017), we might expect to see more works that explore $\mathrm{m} / \mathrm{u}$-learning environments powered by sensors.

In relation to RQ2, results pictured two communities that have produced mature contributions in their fields, as seen from the balanced type of theoretical and practical contributions (Figure 4), $\mathrm{m} / \mathrm{u}$-learning aspects that were considered and evaluated (Figures 5 and 6), and the process of evaluation. Furthermore, LD has proposed contributions that evenly consider the different phases of $\mathrm{LD}$ (Figure 7), while LA shows less diversity over the aspects that were supported. For instance, 


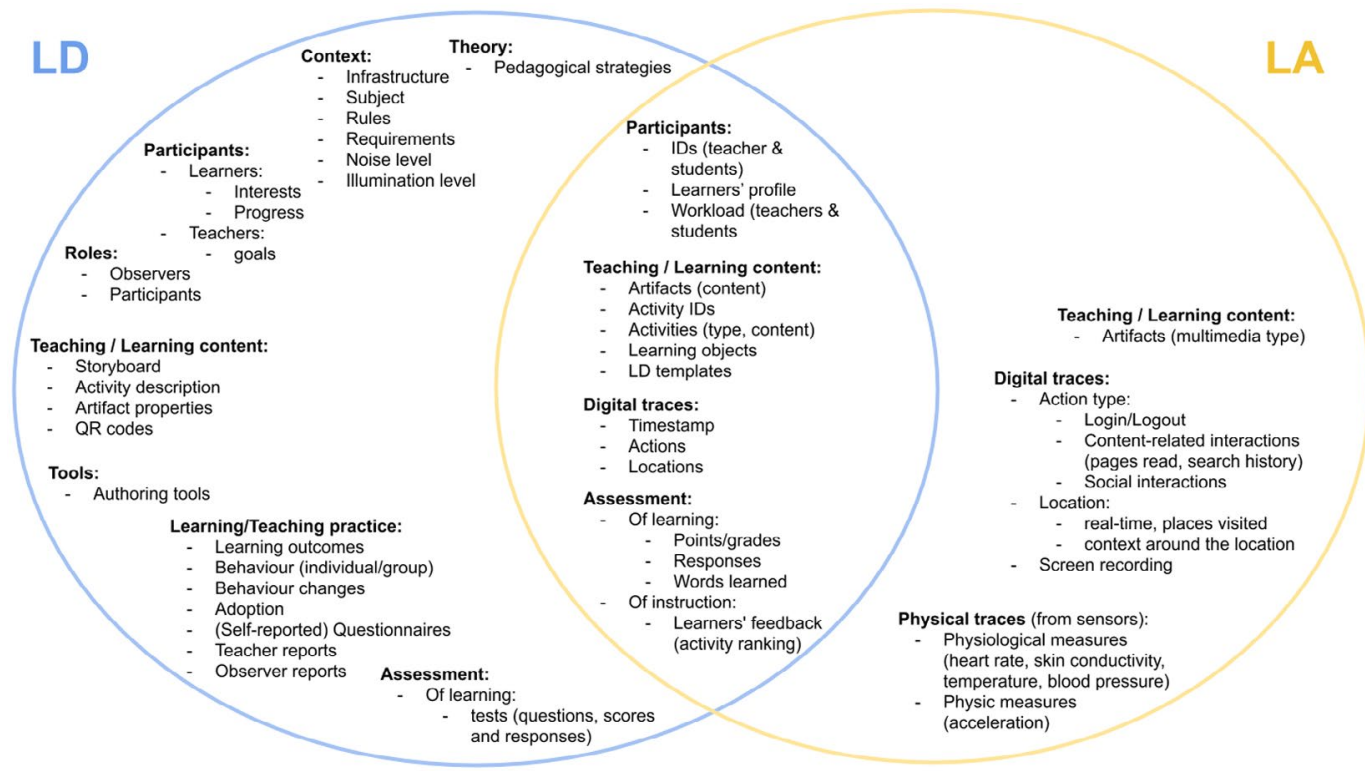

Figure 16: Data used in the papers. On sides data specific to $L D / L A$, in the centre data used by both communities

using the LA Reference Model (Chatti et al., 2013) tutoring and mentoring, adaption, and reflection aspects were underrepresented (Figure 9). This could be due to the specific learning scenarios of the contributions (not requiring focusing on other aspects), or to the novelty of applying LA in $\mathrm{m} / \mathrm{u}$-learning (where the initial focus has been on collecting data, vs. supporting sense and decision making), but it could also signal a missed opportunity to explore other dimensions of LA in m/u-learning. For example, reflection (for students and teachers) could be crucial in connecting learning that happens in different settings (eg, in-classroom and out of the classroom, formal and informal). Now that LA has a better knowledge on collecting data in $\mathrm{m} / \mathrm{u}$-learning, we expect a progressive shift towards supporting sense and decision making, following the general trends in LA (Joksimović, Kovanović, \& Dawson, 2019). Therefore, LD could have a key contribution in this process supporting the contextualization and pedagogical-grounding of the analytics (Persico \& Pozzi, 2015). Also, as part of the interaction with the context, few papers studied social interactions. This aspect could be further supported and explored, enabling learners to develop communication and collaboration skills, and to benefit from the pedagogical benefits of social interactions (Kim \& Baylor, 2006).

Regarding the interplay between LD and LA, the LD-aware monitoring model (Figure 8) pictured an LA community that has produced contributions capable of supporting the different phases of the model (hence, fully supporting LD processes). Nevertheless, despite the mentioned common ground and benefits from the alignment, LD and LA are operating in separate layers (Figure 11). These results might partly be explained by a low number of contributions that are sustainable over time, where results from one specific iteration (eg, lesson learned during one study, from the implementation of specific LA indicators), inform the next cycle of research (eg, the re-designing the learning scenarios used). Such approaches require continuous cooperation between research and educational institutions, and the creation of communities of interested stakeholders around a specific tool (Pishtari, Rodríguez-Triana, \& Väljataga 2019). Indeed, the community layer is underrepresented in the results from the AL4LD framework (Figure 11). The establishment 
of such communities could also generate a layer of support for practitioners' LD/LA practices (Hernández-Leo et al., 2019).

Regarding RQ3, the analyses revealed two unconnected communities, as noted by the low number of papers explicitly addressing both areas (3 out of 54), the sparsely connected co-authorship networks (only three clusters of co-authors addressing both themes), and the lack of connection between those two concepts in the keyword network. Furthermore, even the literature used by those two areas is rather distinct beyond a few common seminal m/u-learning works. Even if the expected benefits of aligning LD and LA have been put forward for quite some years (Lockyer et al., 2013), such connection has still not been widely realized in $\mathrm{m} / \mathrm{u}$-learning.

Despite this disconnection, our review revealed several hinge elements between both communities: the aforementioned common bibliography, terminology, similar learning contexts, or the emphasis on learning and learners. In m/u-learning, both LD/LA solutions already gather data from assessments or the learning context. There are also commonalities in several kinds of topics addressed by both communities: solutions for language learning, guidelines, frameworks and other theoretical contributions. We can also look at the nature of those few papers that addressed both $\mathrm{LD}$ and LA, to understand how those two areas can be connected: guiding interventions while orchestrating (by displaying analytics alongside the different activities of a design for contextualization) or providing analytics that can help understand if a design was effective. Since these practical examples of synergies are still scarce, further research would be necessary to support the LD community with orchestration, design and community analytics solutions, as proposed by Hernández-Leo et al. (2019). Similarly, the guidance that LD provides in the data analysis, interpretation and contextualization could be further exploited as suggested by Rodríguez-Triana et al. (2015).

Our analyses also revealed gaps between the contributions of both communities, that point towards future synergies: m/u-learning analytics solutions can start using design artefacts and constructs, and additional data sources like teacher or observer reports; in turn, design solutions can integrate the plethora of digital and physical traces that are commonplace in LA solutions (Persico \& Pozzi, 2015). Also, joint contributions could be made of types that are relevant in both LD/LA (eg, conceptual frameworks, guidelines or technical architectures), by explicitly joining the insights and previous LD/LA works in m/u-learning.

\section{Conclusion}

Our analysis of the $54 \mathrm{LD} / \mathrm{LA}$ publications in m/u-learning enable us to draw several conclusions. These two communities share common interests, similar learning contexts and offer complimentary support $\mathrm{m} / \mathrm{u}$-learning aspects. Despite the low explicit alignment, most of the papers used analytical solutions to inform LD aspects. Still, a more systematic alignment and coverage of the $\mathrm{LD} / \mathrm{LA}$ processes could contribute to further benefit from the potential synergies. One possible limitation that might be impeding such alignment is the nature of the contributions, more explicitly, the low number of communities of stakeholders around a specific m/u-learning tool, or environment. These communities could enable a sustainable process of researching, which would benefit from complementary LD and LA processes, while also having a direct impact on learning and teaching practices, by creating a layer of support for practitioners.

Further research implications from our results include the need to advance in less explored settings and aspects of $\mathrm{m} / \mathrm{u}$-learning, especially to articulate the transitions between formal and informal learning, and to reinforce the connection across spaces. Other underrepresented research aspects include aligning contributions with specific pedagogical approaches, supporting other aspects apart from monitoring in LA (such as, tutoring and mentoring, or reflection), and 
further study social interactions. Also, increasing the involvement of the different stakeholders in the design and evaluation of the solutions will be crucial to increase their adoption and maturity (Hernández-Leo et al., 2019). In connection with the recent trends towards aligning LD and LA in other settings, we expect this review lead to more synergies in $\mathrm{m} / \mathrm{u}$-learning in the near future.

\section{Acknowledgements}

This research was partially funded by EU grants 669074, 586120-EPP-1-2017-1-ES-EPPKA2CBHE-JP, and Spanish projects TIN2017-85179-C3-1-R, TIN2017-85179-C3-2-R, TIN201785179-C3-3-R, VA257P18.

\section{Statements on open data, ethics and conflict of interest}

Requests for the data can be addressed to the corresponding author.

Approval for conducting this research was received from Tallinn University.

There are no potential conflicts of interest.

\section{References}

Abdurrahman, J., Beer, M., \& Crowther, P. (2015). Pedagogical requirements for mobile learning: A review on MOBIlearn task model. Journal of Interactive Media in Education, 2015(1), 1-17. https://doi. org/10.5334/jime.ap

Aljohani, N. R., \& Davis, H. C. (2012). Learning analytics in mobile and ubiquitous learning environments. In M. Specht, M. Sharples \& J. Multisilta (Eds), Proceedings of the 11th world conference on mobile and contextual learning: mLearn 2012 (pp. 70-77). Helsinki, Finland.

Aljohani, N. R., \& Davis, H. C. (2013). Learning analytics and formative assessment to provide immediate detailed feedback using a student centered mobile dashboard. In K. Al-Begain, R. Bestak, N. Al-Beiruti \& C. Turyagyenda (Eds.), 2013 Seventh international conference on next generation mobile apps, services and technologies (pp. 262-267). Prague, Czech republic: IEEE. https://doi.org/10.1109/NGMAST.2013.54

Bassani, P. B. S., \& Barbosa, D. N. F. (2018, July). Designing for authorship: Students as content creators using mobile devices in educational settings. In International conference on learning and collaboration technologies (pp. 3-19). Cham, Switzerland: Springer.

Chatti, M. A., Dyckhoff, A. L., Schroeder, U., \& Thüs, H. (2013). A reference model for learning analytics. International Journal of Technology Enhanced Learning, 4(5-6), 318-331. https://doi.org/10.1504/ IJTEL.2012.051815

Chounta, I. A., Giemza, A., \& Hoppe, H. U. (2014, September). Multilevel analysis of collaborative activities based on a mobile learning scenario for real classrooms. In T. Yuizono, G. Zurita, N. Baloian, T. Inoue, \& H. Ogata (Eds.), Collaboration technologies and social computing. CollabTech 2014. Communications in Computer and Information Science, 460 (pp. 127-142). Berlin, Heidelberg: Springer. https://doi.org/10.1007/9783-662-44651-5_12

Churchill, D., Fox, B., \& King, M. (2016). Framework for designing mobile learning environments. In D. Churchill, J. Lu, T. Chiu, \& B. Fox (Eds.), Mobile learning design. Lecture Notes in Educational Technology (pp. 3-25). Singapore, Singapore: Springer. https://doi.org/10.1007/978-981-10-0027-0_1

Cochrane, T., Antonczak, L., Guinibert, M., Mulrennan, D., Rive, V., \& Withell, A. (2017). A framework for designing transformative mobile learning. In A. Murphy, H. Farley, L. Dyson, \& H. Jones (Eds.), Mobile learning in higher education in the Asia-Pacific region. Education in the Asia-Pacific region: Issues, concerns and prospects, 40 (pp. 25-43). Singapore, Singapore: Springer. https://doi.org/10.1007/978-981-10-4944-6_2

Cooner, T. S., Knowles, A., \& Stout, B. (2016). Creating a mobile app to teach ethical social media practices. Social Work Education, 35(3), 245-259. https://doi.org/10.1080/02615479.2015.1042361. 
Fu, Q. K., \& Hwang, G. J. (2018). Trends in mobile technology-supported collaborative learning: A systematic review of journal publications from 2007 to 2016. Computers \& Education, 119, 129-143. https:// doi.org/10.1016/j.compedu.2018.01.004

Fulantelli, G., Taibi, D., \& Arrigo, M. (2013, November). A semantic approach to mobile learning analytics. In Proceedings of the First International Conference on Technological Ecosystem for Enhancing Multiculturality. (TEEM '13) (pp. 287-292). New York, NY: Association for Computing Machinery. https://doi. org/10.1145/2536536.2536579

Fulantelli, G., Taibi, D., \& Arrigo, M. (2015). A framework to support educational decision making in mobile learning. Computers in Human Behavior, 47, 50-59. https://doi.org/10.1016/j.chb.2014.05.045

Glahn, C. (2013, September). Using the adl experience api for mobile learning, sensing, informing, encouraging, orchestrating. In K. Al-Begain, R. Bestak, N. Al-Beiruti \& C. Turyagyenda (Eds.), 2013 Seventh International Conference on Next Generation Mobile Apps, Services and Technologies (pp. 268-273). Prague, Czech republic: IEEE. https://doi.org/10.1109/NGMAST.2013.55

Gómez, S., Zervas, P., Sampson, D. G., \& Fabregat, R. (2012, July). Delivering adaptive and context-aware educational scenarios via mobile devices. In 2012 IEEE 12th International Conference on Advanced Learning Technologies (pp. 197-201). Rome, Italy: IEEE. https://doi.org/10.1109/ICALT.2012.200

Gómez, S., Zervas, P., Sampson, D. G., \& Fabregat, R. (2014). Context-aware adaptive and personalized mobile learning delivery supported by UoLmP. Journal of King Saud University-Computer and Information Sciences, 26(1), 47-61. https://doi.org/10.1016/j.jksuci.2013.10.008

Hasnine, M. N., Mouri, K., Flanagan, B., Akcapinar, G., Uosaki, N., \& Ogata, H. (2018). Image recommendation for informal vocabulary learning in a context-aware learning environment. In J. C. Yang et al (Eds.), Proceedings of the 26th International Conference on Computer in Education (pp. 669-674). Philippines, Asia: Asia-Pacific Society for Computers in Education.

Hernández-Leo, D., Asensio-Pérez, J. I., Derntl, M., Prieto, L. P., \& Chacón, J. (2014, September). ILDE: Community environment for conceptualizing, authoring and deploying learning activities. In European conference on technology enhanced learning (pp. 490-493). Cham, Switzerland: Springer.

Hernández-Leo, D., Martinez-Maldonado, R., Pardo, A., Muñoz-Cristóbal, J. A., \& Rodríguez-Triana, M. J. (2019). Analytics for learning design: A layered framework and tools. British Journal of Educational Technology, 50(1), 139-152. https://doi.org/10.1111/bjet.12645

Hernández-Leo, D., \& Pardo, A. (2016). Towards integrated learning design with across-spaces learning analytics: a flipped classroom example. In R. Martínez-Maldonado \& D. Hernádez-Leo (Eds.), Proceedings of the First International Workshop on Learning Analytics Across Physical and Digital Spaces co-located with 6th International Conference on Learning Analytics \& Knowledge (LAK 2016) (pp. 25-29). Edinburgh, Scotland. CEUR Workshop Proceedings.

Huang, W. D., \& Andrade, J. (2014). Design and evaluation of mobile learning from the perspective of cognitive load management. In J. Yoder, A. DeMarco \& K. Wolfe (Eds.) Handbook of Research on Education and Technology in a Changing Society (pp. 291-306). Florida: IGI Global. https://doi.org/10.4018/978-14666-6046-5.ch022

Hwang, G. J., \& Tsai, C. C. (2011). Research trends in mobile and ubiquitous learning: A review of publications in selected journals from 2001 to 2010. British Journal of Educational Technology, 42(4), E65-E70. https://doi.org/10.1111/j.1467-8535.2011.01183.x

Hwang, G. J., \& Wu, P. H. (2014). Applications, impacts and trends of mobile technology-enhanced learning: a review of 2008-2012 publications in selected SSCI journals. International Journal of Mobile Learning and Organisation, 8(2), 83-95. https://doi.org/10.1504/IJMLO.2014.062346

Imtinan, U., Chang, V., \& Issa, T. (2013). Common mobile learning characteristics - An analysis of mobile learning models and frameworks. In A. Sanchez \& P. Isaias (Eds.), Mobile Learning 2013. Proceedings of the International Conference Mobile Learning 2013 (pp. 3-11). Lisbon, Portugal: IADIS Press. Retrieved from http://hdl.handle.net/20.500.11937/21348

Jerez, A. R., Guenaga, M., \& Núñez, A. (2014, April). A web platform for the assessment of competences in Mobile Learning Contexts. In 2014 IEEE Global Engineering Education Conference (EDUCON) (pp. 321-329). IEEE.

Jesse, R., \& Chang, M. (2012, March). Using IMS learning design to author authentic learning examples in mobile context. In 2012 IEEE Seventh International Conference on Wireless, Mobile and Ubiquitous Technology in Education (pp. 167-171). Takamatsu, Japan: IEEE. https://doi.org/10.1109/WMUTE.2012.38 
Joksimović, S., Kovanović, V., \& Dawson, S. (2019). The journey of learning analytics. HERDSA Review of Higher Education, 6, 27-63.

Kim, Y., \& Baylor, A. L. (2006). A social-cognitive framework for pedagogical agents as learning companions. Educational Technology Research and Development, 54(6), 569-596.

Kitchenham, B., \& Charters, S. (2007). Guidelines for performing systematic literature reviews in software engineering. Staffordshire, Durham: EBSE 2007-001 Technical Report. Keele University and Durham University Joint Report.

Liu, G. Z., Hwang, G. J., Kuo, Y. L., \& Lee, C. Y. (2014). Designing dynamic English: A creative reading system in a context-aware fitness centre using a smart phone and QR codes. Digital Creativity, 25(2), 169-186. https://doi.org/10.1080/14626268.2013.836110

Liu, G. Z., Liu, T. C., Lin, C. C., Kuo, Y. L., \& Hwang, G. J. (2016). Identifying learning features and models for context-aware ubiquitous learning with phenomenological research method. International Journal of Mobile Learning and Organisation, 10(4), 238-262. https://doi.org/10.1504/IJMLO.2016.079501

Lkhagvasuren, E., Matsuura, K., Mouri, K., \& Ogata, H. (2016). Dashboard for analyzing ubiquitous learning log. International Journal of Distance Education Technologies, 14(3), 1-20. https://doi.org/10.4018/ IJDET.2016070101

Lockyer, L., Heathcote, E., \& Dawson, S. (2013). Informing pedagogical action: Aligning learning analytics with learning design. American Behavioral Scientist, 57(10), 1439-1459. https://doi.org/10.1177/00027 64213479367

Loewen, J. (2009, December). The study and application of IMS learning design specifications in a mobile context. In 2009 Joint Conferences on Pervasive Computing (JCPC) (pp. 39-44). Tamsui, Taipei, Taiwan: IEEE. https://doi.org/10.1109/JCPC.2009.5420215

Mangaroska, K., \& Giannakos, M. N. (2018). Learning analytics for learning design: A systematic literature review of analytics-driven design to enhance learning. IEEE Transactions on Learning Technologies, 12(4), 516-534. https://doi.org/10.1109/TLT.2018.2868673

Melero, J., Hernández-Leo, D., Sun, J., Santos, P., \& Blat, J. (2015). How was the activity? A visualization support for a case of location-based learning design. British Journal of Educational Technology, 46(2), $317-$ 329. https://doi.org/10.1111/bjet.12238

Mikroyannidis, A., Gómez-Goiri, A., Smith, A., \& Domingue, J. (2018). PT Anywhere: A mobile environment for practical learning of network engineering. Interactive Learning Environments, 1-15. https://doi. org/10.1080/10494820.2018.1541911

Mor, Y., Ferguson, R., \& Wasson, B. (2015). Learning design, teacher inquiry into student learning and learning analytics: A call for action. British Journal of Educational Technology, 46(2), 221-229. https:// doi.org/10.1111/bjet.12273

Mor, Y., \& Mogilevsky, O. (2012, October). A learning design studio in mobile learning. In M. Specht, M. Sharples \& J. Multisilta (Eds.), Proceedings of the 11th international conference on mobile and contextual learning 2012 (pp. 262-265). Helsinki, Finland: CEUR. http://dx.doi.org/10.3402/rlt.v21i0.22054

Mouri, K., \& Ogata, H. (2015). Ubiquitous learning analytics in the real-world language learning. Smart Learning Environments, 2(1), 15. https://doi.org/10.1186/s40561-015-0023-x

Mouri, K., Ogata, H., \& Uosaki, N. (2015a). Analysis of ubiquitous learning logs using social network analysis. International Journal of Mobile Learning and Organisation, 9(2), 101-123. https://doi.org/10.1504/ IJMLO.2015.070702.

Mouri, K., Ogata, H., \& Uosaki, N. (2015b). Recommendation method in the context of real-world language learning. In H. Ogata, W. Chen, S. C. Kong, \& F. Qiu (Eds.), Workshop of the 23rd International Conference on Computers in Education (2015d) (pp. 704-712). Hangzhou, China: Asia-Pacific Society for Computers in Education.

Mouri, K., Ogata, H., Uosaki, N., \& Lkhagvasuren, E. (2016). Context-aware and personalization method based on ubiquitous learning analytics. J. UCS, 22(10), 1380-1397. https://doi.org/10.3217/ jucs-022-10-1380

Mouri, K., Uosaki, N., \& Ogata, H. (2018). Learning analytics for supporting seamless language learning using e-book with ubiquitous learning system. Journal of Educational Technology \& Society, 21(2), 150163. Retrieved from https://www.jstor.org/stable/26388390 
Muñoz-Cristóbal, J. A., Martínez-Monés, A., Asensio-Pérez, J. I., Villagrá-Sobrino, S., Hoyos-Torio, J. E., \& Dimitriadis, Y. A. (2014). City Ads: Embedding virtual worlds and augmented reality in everyday educational practice. J. UCS, 20(12), 1670-1689. https://doi.org/10.3217/jucs-020-12-1670

Muñoz-Cristóbal, J. A., Prieto, L. P., Asensio-Pérez, J. I., Martínez-Monés, A., Jorrín-Abellán, I. M., \& Dimitriadis, Y. (2014). Deploying learning designs across physical and web spaces: Making pervasive learning affordable for teachers. Pervasive and Mobile Computing, 14, 31-46. https://doi.org/10.1016/j. pmcj.2013.09.005

Muñoz-Cristóbal, J. A., Rodríguez-Triana, M. J., Gallego-Lema, V., Arribas-Cubero, H. F., Asensio-Pérez, J. I., \& Martínez-Monés, A. (2018). Monitoring for awareness and reflection in ubiquitous learning environments. International Journal of Human-Computer Interaction, 34(2), 146-165. https://doi. org/10.1080/10447318.2017.1331536

Ochoa, X. (2017). Multimodal learning analytics. The Handbook of Learning Analytics, 129-141.

Ogata, H., Liu, S., \& Mouri, K. (2014, January). Ubiquitous learning analytics using learning logs. In 4th International Conference on Learning Analytics and Knowledge, LAK 2014. Indianapolis Indiana USA CEUR Workshop Proceedings. New York, NY: Association for Computing Machinery.

Pappas, I. O., Giannakos, M. N., \& Sampson, D. G. (2017). Fuzzy set analysis as a means to understand users of 21st-century learning systems: The case of mobile learning and reflections on learning analytics research. Computers in Human Behavior, 92, 646-659. https://doi.org/10.1016/j.chb.2017.10.010

Parsons, D., Ryu, H., \& Cranshaw, M. (2006, July). A study of design requirements for mobile learning environments. In Sixth IEEE International Conference on Advanced Learning Technologies (ICALT'06) (pp. 96-100). Kerkrade, Netherlands: IEEE. https://doi.org/10.1109/ICALT.2006.1652376

Paulins, N., Balina, S., \& Arhipova, I. (2015). Learning content development methodology for mobile devices. Procedia Computer Science, 43, 147-153. https://doi.org/10.1016/j.procs.2014.12.020

Pawar, R. S., Sobhgol, S., Durand, G. C., Pinnecke, M., Broneske, D., \& Saake, G. (2019). Codd's World: Topics and their Evolution in the Database Community Publication Graph. In Proceedings of the 31st GI-Workshop Grundlagen von Datenbanken (pp. 74-81). Saarburg, Germany. http://ceur-ws.org/Vol-2367/paper_3.pdf

Persico, D., \& Pozzi, F. (2015). Informing learning design with learning analytics to improve teacher inquiry. British Journal of Educational Technology, 46(2), 230-248. https://doi.org/10.1111/bjet.12207.

Pimmer, C., Mateescu, M., \& Gröhbiel, U. (2016). Mobile and ubiquitous learning in higher education settings. A systematic review of empirical studies. Computers in Human Behavior, 63, 490-501. https://doi. org/10.1016/j.chb.2016.05.057

Pishtari, G., Rodríguez-Triana, M. J., Sarmiento-Márquez, E. M., Terasmaa, J., Kori, K., ... Puusepp, L. (2019, September). An overview of learning design and analytics in mobile and ubiquitous learning. In M. Herzog, Z. Kubincová, P. Han, \& M. Temperini (Eds.), Advances in Web-Based Learning-ICWL 2019, 11841 (pp. 312-319). Cham, Switzerland: Springer. https://doi.org/10.1007/978-3-030-35758-0_30

Pishtari, G., Rodríguez-Triana, M. J., \& Väljataga, T. (2019, September). Multi-stakeholder analytics for learning design: A case study of location-based tools. In World Conference on Mobile and Contextual Learning (pp. 94-101). Retrieved from https://www.learntechlib.org/p/210606/

Power, R. (2018). Supporting mobile instructional design with CSAM. In S. Yu, M. Ally \& A. Tsinakos (Eds.), Mobile and ubiquitous learning. An international handbook (pp. 193-209). Singapore, Singapore: Springer. https://doi.org/10.1007/978-981-10-6144-8_12

Rodríguez-Triana, M. J., Martínez-Monés, A., Asensio-Pérez, J. I., \& Dimitriadis, Y. (2015). Scripting and monitoring meet each other: Aligning learning analytics and learning design to support teachers in orchestrating CSCL situations. British Journal of Educational Technology, 46(2), 330-343. https://doi. org/10.1111/bjet.12198

Ruhalahti, S., Korhonen, A. M., \& Rasi, P. (2017). Authentic, dialogical knowledge construction: A blended and mobile teacher education programme. Educational Research, 59(4), 373-390. https://doi. org/10.1080/00131881.2017.1369858

Schneider, J., Di Mitri, D., Limbu, B., \& Drachsler, H. (2018, September). Multimodal learning hub: A tool for capturing customizable multimodal learning experiences. In European Conference on Technology Enhanced Learning (pp. 45-58). Cham, Switzerland: Springer. https://doi.org/10.1007/978-3-319-98572-5_4

Schwendimann, B. A., Rodriguez-Triana, M. J., Vozniuk, A., Prieto, L. P., Boroujeni, M. S., Holzer, A., ... Dillenbourg, P. (2016). Perceiving learning at a glance: A systematic literature review of learning 
dashboard research. IEEE Transactions on Learning Technologies, 10(1), 30-41. https://doi.org/10.1109/ TLT.2016.2599522

Seiler, L., Kuhnel, M., Ifenthaler, D., \& Honal, A. (2019). Digital applications as smart solutions for learning and teaching at higher education institutions. In D. Ifenthaler, D.-K. Mah \& J. Y.-K. Yau (Eds.), Utilizing learning analytics to support study success (pp. 157-174). Cham, Switzerland: Springer. https://doi. org/10.1007/978-3-319-64792-0_10

Sharples, M., Taylor, J., \& Vavoula, G. (2010). A theory of learning for the mobile age. In B. Bachmair (Ed.), Medienbildung in neuen Kulturräumen (pp. 87-99). VS Verlag für Sozialwissenschaften, Springer.

Shorfuzzaman, M., Hossain, M. S., Nazir, A., Muhammad, G., \& Alamri, A. (2019). Harnessing the power of big data analytics in the cloud to support learning analytics in mobile learning environment. Computers in Human Behavior, 92, 578-588. https://doi.org/10.1016/j.chb.2018.07.002

Siadaty, M., Torniai, C., Gašević, D., Jovanovic, J., Eap, T., \& Hatala, M. (2008, June). m-LOCO: An ontology-based framework for context-aware mobile learning. In B. Woolf, E. Aïmeur, R. Nkambou \& S. Lajoie (Eds.), Proc. of the 6th Int. Workshop on Ontologies and Semantic Web for Intelligent Educational Systems at the 9th International Conference on Intelligent Tutoring Systems, ITS 2008, Montreal, Canada (pp. 21-35). Springer.

Stanton, G., \& Ophoff, J. (2013, July). Towards a method for mobile learning design. In E. Cohen \& E. Boyd (Eds.), Proceedings of the Informing Science and Information Technology Education Conference 2013, (pp. 501523). Porto, Portugal: Informing Science Institute. https://www.learntechlib.org/p/114701/

Sun, D., Looi, C. K., Wu, L., \& Xie, W. (2016). The innovative immersion of mobile learning into a science curriculum in Singapore: An exploratory study. Research in Science Education, 46(4), 547-573. https:// doi.org/10.1007/s11165-015-9471-0

Tabuenca, B., Kalz, M., Drachsler, H., \& Specht, M. (2015). Time will tell: The role of mobile learning analytics in self-regulated learning. Computers \& Education, 89, 53-74. https://doi.org/10.1016/j.compe du.2015.08.004

Teall, E., Wang, M., Callaghan, V., \& Ng, J. W. (2014). An exposition of current mobile learning design guidelines and frameworks. International Journal on E-Learning, 13(1), 79-99. Retrieved from https://www. learntechlib.org/primary/p/39331/

Ting, Y. L. (2013). Using mobile technologies to create interwoven learning interactions: An intuitive design and its evaluation. Computers \& Education, 60(1), 1-13. https://doi.org/10.1016/j.compe du.2012.07.004

Traxler, J. (2009). Learning in a mobile age. International Journal of Mobile and Blended Learning, 1(1), 1-12. https://doi.org/10.4018/jmbl.2009010101

Wang, M., Xiao, J., Chen, Y., \& Min, W. (2014, June). Mobile learning design: The LTCS model. In 2014 International Conference on Intelligent Environments (pp. 318-325). Shanghai, China: IEEE. https://doi. org/10.1109/IE.2014.68

Wong, G. K. (2016). A new wave of innovation using mobile learning analytics for flipped classroom. In D. Churchill, J. Lu, T. Chiu, \& B. Fox (Eds.), Mobile learning design. Lecture Notes in Educational Technology (pp. 189-218). Singapore, Singapore: Springer. https://doi.org/10.1007/978-981-10-0027-0_12

Wong, L. H., \& Looi, C. K. (2018). Authentic learning of primary school science in a seamless learning environment: A meta-evaluation of the learning design. In T. W. Chang, R. Huang, \& R. Kinshuk (Eds.), Authentic learning through advances in technologies. Lecture Notes in Educational Technology (pp. 137-170) Singapore, Singapore: Springer. https://doi.org/10.1007/978-981-10-5930-8_9

Yamada, M., Okubo, F., Oi, M., Shimada, A., Kojima, K., \& Ogata, H. (2016, January). Learning analytics in ubiquitous learning environments: Self-regulated learning perspective. In ICCE 2016-24th International Conference on Computers in Education: Think Global Act Local - Main Conference Proceedings (pp. 306-314). Mumbai India: Asia-Pacific Society for Computers in Education.

Zervas, P., Ardila, S. E. G., Fabregat, R., \& Sampson, D. G. (2011). Designing tools for context-aware adaptive mobile learning. In A. Ghoneim, M. Themistocleous, D. Koufopoulos \& M. Kamal (Eds.), Proceedings of the European, Mediterranean \& Middle Eastern Conference on Information Systems (pp. 720-726). Athens, Greece: EMCIS. 